Research Article

\title{
Use of complementary and alternative medicine and factors affecting their use among Libyan children with rheumatic diseases at Tripoli Children's Hospital 2019
}

\begin{abstract}
Background: Complementary and alternative medicine (CAM) is defined as a group of diverse medical and health care systems, practices, and products that are not presently considered as conventional medicine.

Aim of the study: To determine the prevalence, types, and factors affecting use of complementary and alternative medicine among Libyan children with rheumatic diseases.

Methodology: A descriptive cross-sectional study was conducted in rheumatology clinic at Tripoli Children's Hospital, in which parents of children with different rheumatic diseases were interviewed by using a pre formed questionnaire at their routine visits. Data were managed and analyzed by SPSS data base (version 19).

Result: Of 103 interviewed parents, 71(69\%) were mothers with mean age of 41.21 years, $39 \%$ of whom had a university degree, and $50 \%$ of whom were employed. $31 \%$ were fathers with mean age of 47.7 years, $74 \%$ of whom were employed and $38 \%$ of whom had a university degree. $65 \backslash 103(63 \%)$ of parents were living outside Tripoli. Majority of patients were females $(75 \%)$ with a mean age of 12.8 years, $95 \%$ of the patients living with both their father and mother together.

$63 \%$ of patients had juvenile idiopathic arthritis. Overall, $83 \%$ of patients were CAM users, $77 \%$ of theme was females and $65 \%$ had been diagnosed as JIA. The most frequently used CAM were Natural health products $(69.8 \%)$ as honey and Meringa. Almost all CAM users $(96.5 \%)$ did not change or stop their conventional therapy nor did they deviate from their scheduled visits in the rheumatology clinic.

Conclusion \& recommendation: CAM use was common among patients followed in the pediatric rheumatology clinic; Natural health products were the most commonly used CAM. Very little is known about the benefits or potential harms of CAM despite its widespread use. Education and counseling programs to patients and parents about CAM use can help in the management of such chronic diseases.
\end{abstract}

Keywords: complementary and alternative medicine, children, rheumatic disease
Volume I 3 Issue I - 202 I

\author{
Fawzea M Almsagri,' Mabruka M Zletni, ${ }^{2}$ \\ Jamal S Meezogi, ${ }^{1}$ Aisha Ben Rewen, ${ }^{3}$ Salmin \\ K Shalmani, ${ }^{4}$ Awatif Abushhaiwia ${ }^{2}$ \\ 'Department of Pharmacognosy, Faculty of pharmacy, University \\ of Tripoli, Libya \\ ${ }^{2}$ Department of Pediatrics, Faculty of medicine, University of \\ Tripoli, Libya \\ ${ }^{3}$ Department of Family medicine, Faculty of medicine, University \\ of Tripoli, Libya \\ ${ }^{4}$ Department of Pharmacognosy, Faculty of pharmacy, University \\ of Benghazi, Libya
}

\author{
Correspondence: Fawzea Mustafa Almsagri, Clinical \\ pharmacist, Department of rheumatology, Tripoli Children \\ Hospital, Libya, Tel 002 I89 I I47889, \\ Email fawaziaalmsakr@gmail.com
}

Received: February 18, 202। | Published: February 26, 2021

\section{Introduction}

World Health Organization (WHO) defined Complementary and Alternative Medicine as a broad set of healthcare practices that are not integrated into the dominant healthcare system. ${ }^{1}$ It is estimated that $80 \%$ of the world's populations depend on indigenous therapies to treat or at least to minimize patient complain. ${ }^{2}$ The use of CAM has increased over all the world; in Saudi Arabia $46 \%$ of the patients in the health facilities had used CAM at some time in the past. In Africa up to $80 \%$ of the population uses complementary and alternative medicine, In China CAM accounts for around $40 \%$ of all health care delivered. The percentage of the population in developed countries which has used CAM at least once is $48 \%$ in Australia, $70 \%$ in Canada, $42 \%$ in USA, 38\% in Belgium and 75\% in France.

Studies in pediatric populations have shown that CAM use in the general pediatric population ranges between 20 and $40 \%{ }^{4,5}$ while between $50-72 \%$ of children with chronic diseases such as asthma and inflammatory bowel disease use CAM. ${ }^{4,6}$

Only limited number of studies discussed the use of CAM in pediatric rheumatology patients. ${ }^{6}$ South wood et al. ${ }^{7}$ surveyed 53 patients with juvenile idiopathic arthritis attending arthritis youth camps and reported that $70 \%$ of theme used CAM.

In 202 patients with juvenile idiopathic arthritis and other types of rheumatic diseases participated in a survey at Floating Hospital in Tufts Medical Centre, $50 \%$ of theme had used CAM, and large number of themes had family history of CAM use. A high education level and disease duration were associated factors. ${ }^{8}$

$56 \%$ of Latino patient attended pediatric rheumatology clinic at a Midwest tertiary care children's hospital with juvenile idiopathic arthritis and arthralgia used CAM to reduce joint pain, CAM was helpful in reducing anxiety and depression only in patients with artharlgia, in half of the cases using CAM was not advised or discussed from their clinicians. ${ }^{9}$

It is estimated that $90 \backslash 141(64 \%)$ patient in pediatric rheumatology clinic in Toronto, Ontario, and Canada used at least one type of CAM, $50 \%$ of those patients had co morbidities. Use of CAM was related to longer disease duration and presence of co morbidities. The most common types of CAM used were vitamins and minerals. ${ }^{10}$ 
In 118 patients with juvenile idiopathic arthritis who attended rheumatology clinic at two pediatric hospitals (Montreal Children's Hospital-McGill University Health Centre and British Columbia's Children's Hospital), ever use CAM was $33.9 \%$ and was higher in patients whose parents used CAM before, also CAM use was not related to decrease adherence to conventional medical therapy. ${ }^{11}$

CAM use was highly associated with parental use of CAM and possibly longer disease duration in patient with juvenile idiopathic arthritis. ${ }^{12}$ Hagen et al also found that disease duration was strongly associated with CAM use.

$10 \%$ of the patient attending rheumatology clinic at the Pediatric Rheumatology Centre of University of Padua in Italy used CAM, increased to $24 \%$ in patient who escaped from the clinic. Homeopathy, herbal remedies, vitamins and minerals were the most commonly CAM used by all patients. Italian CAM users had parents with a high level of education indicates that access to CAM is mainly restricted to high income families, usually over-informed and worried about the potential side effects of traditional treatments. ${ }^{13}$

According to the National Centre for Complementary and Alternative Medicine NCCAM, complementary therapies include natural products and mind body therapies. Natural products include, animal-derived extracts, vitamins, minerals, fatty acids, amino acids, proteins, prebiotics and probiotics, whole diets, and functional foods. Of these, multivitamins are the most frequently used CAM products by children, with up to $41 \%$ reported usage. Among teenagers who use CAM, nearly $75 \%$ use herbs and other dietary supplements. ${ }^{13}$

Herbal medicine is the most commonly used CAM in USA, $38 \%$ of the population using it. Soner et al. ${ }^{13}$ reported that $48.8 \%$ of people use herbal medicine in Turkey. Massage, a type of CAM used as routine practice in neonatal intensive care unit to potentiate growth and development in preterm infants also used to relive some symptoms of asthma, insomnia, colic, cystic fibrosis, and juvenile idiopathic arthritis.

People who suffer from chronic diseases and who have used multiple medications are more likely to use herbals to prevent or treat diseases because they think that the herbal medicine are harmless and safer even though they might have side effects. ${ }^{14}$

Acupuncture is used by pediatric patients in the treatment of recurrent headaches, nausea, pain, and allergy. ${ }^{13}$ Cupping used in treatment of many conditions such as chronic muscle pain, lower back pain, neuralgia pain, fibromyalgia, headache and migraine. In some countries like China and Korea, cupping therapy has been applied as a formal modality in hospitals and act as a complementary medicine. ${ }^{15}$

The earliest discovery of reflexology was found in Egypt which was based on the observation of daily life activities including the medical practices. Today reflexology is considered as recent CAM which based on traditional beliefs, theories and cultures. ${ }^{16}$

Allah was given a powerful system of therapy both for the spirit and the human body to the prophet Mohammed. The appearance of the prophet therapy in the Arab countries was justified because it goes along the basic Islamic instructions. The use of traditional Islamic therapy by Muslims is known as ATibb Al-Nabaw. One of the most applied practices is Alhijama or cupping in Western world, for hundreds of years Alhijama was the most commonly applied traditional therapy among Arab world used for the treatment of many illnesses such as hypertension, musculoskeletal pain, heart disease. ${ }^{17}$ Saudi Arabia tops the ranking of scientific research output in complementary medicine among Arab countries according to a bibliometric analysis published in 2015, Saudi Arabia was 25\% followed by Egypt (16.8\%) and then Morocco $(16.2 \%){ }^{18}$

\section{Aim of study}

To determine the prevalence, types, and factors affecting use of complementary and alternative medicine among Libyan children with rheumatic diseases.

\section{Methodology}

This study conducted with cross sectional design, during the period from the 1st of February 2019 to the end of March 2019. All Libyan parents of children with rheumatic diseases attending outpatient rheumatology clinic at Tripoli children hospital during the period of study were involved. 103 parents of patients participated in the study by filling a pre formed questionnaire. The questionnaire was self and interviewer administrated and the response was collected during the same visit. The purpose of the questionnaire was explained to the parents and their verbal consent was taken to be included in the study.

The questionnaire was modified from a Canadian questionnaire assessing complementary and alternative medicine use in pediatric rheumatology named WHAT questionnaire. (WHAT, Health approaches And Treatments are you using? ${ }^{19}$ The questionnaire consisted of three sections ,the first section contained demographic data for patients and parents like (age, sex, education level address, order of the child in the family, family size, who fill the questionnaire, the child living with whom, age, education, and occupation of mother and father) The second section contained disease data (diagnosis of disease, disease duration, co morbidity, and any drugs taken by the patient) and the third section of questionnaire contained nine questions about use of complementary and alternative medicine in the past, recent use of CAM and future planning of CAM use. The English version of the questionnaire was modified to be more culturally relevant by adding some types of CAM such as rukia and cautery, and removing some types as imagery and hypnosis. English version of questionnaire was translated to Arabic language and reviewed by an Arabic language expertise for language correction. A pilot study was done to assess the questionnaire validity, and patients still under investigation or with no proven diagnosis were excluded from the study.

Data management \& analysis: Data was managed by the statistical package for the social sciences (SPSS version 19). The descriptive statistics (percent, frequency, mean, standard deviation and range) and inferential statistical tests (Chi-square test) was used in Significance level of $5 \%$.

\section{Result}

Among 103 study participants, 71 mothers answered the questionnaire $(69 \%)$ versus 32 fathers (31\%). Mother's age ranged from 26 to 60 years with mean age of 41.21 years, $40(39 \%)$ of mothers had a university degree, and 51(50\%) were employer. On the other hand, fathers age ranged from 33 to 75 years with a mean of 47.73 years. Most of fathers 76 (74\%) were employed and 39 (38\%) had a university degree, $63 \%$ of the participant were living outside Tripoli. As shown in Table 1.

The patients were mostly females (75\%) with a mean age of 12.8 years, $95 \%$ of them living with both father and mother together and nearly half of them $(47 \%)$ were at primary school level, $67 \%$ of them were living in small families with one to four children and $27 \%$ were the first child in the family as shown in Table 2 . 
Table I Demographic data of parents of CAM user VS non user

\begin{tabular}{|c|c|c|c|c|}
\hline Characteristic & & CAM user & non user & $P$ value \\
\hline \multirow[t]{2}{*}{ Who filled the questionnaire } & Mother & 60 & 11 & 0.682 \\
\hline & Father & 26 & 6 & \\
\hline \multirow[t]{6}{*}{ Mother education level } & Illiterate & 8 & 0 & \\
\hline & Primary & 8 & 3 & 0.865 \\
\hline & Preparatory & 12 & 2 & \\
\hline & Secondary & 22 & 5 & \\
\hline & University & 35 & 5 & \\
\hline & Postgraduate & 0 & I & \\
\hline \multirow[t]{6}{*}{ Father education level } & Illiterate & 2 & 0 & 0.537 \\
\hline & Primary & 4 & 0 & \\
\hline & Preparatory & 13 & 3 & \\
\hline & Secondary & 31 & 5 & \\
\hline & University & 31 & 8 & \\
\hline & Postgraduate & 3 & 0 & \\
\hline \multirow[t]{2}{*}{ Mother occupation } & House wife & 40 & 10 & 0.259 \\
\hline & Employer & 45 & 6 & \\
\hline \multirow[t]{4}{*}{ Father occupation } & Employer & 64 & 12 & 0.9 \\
\hline & Unemployed & 8 & 2 & \\
\hline & Retired & 8 & 0 & \\
\hline & Businessman & 6 & 2 & \\
\hline \multirow[t]{4}{*}{ Mother age } & $25-34$ & 15 & 6 & 0.043 \\
\hline & $35-44$ & 41 & 6 & \\
\hline & $45-54$ & 25 & 4 & \\
\hline & $55-64$ & 4 & 0 & \\
\hline \multirow[t]{5}{*}{ Father age } & $33-44$ & 29 & 7 & 0.407 \\
\hline & $45-54$ & 39 & 6 & \\
\hline & $55-64$ & 10 & 3 & \\
\hline & $65-74$ & 5 & 0 & \\
\hline & $75-84$ & 1 & 0 & \\
\hline
\end{tabular}

Table 2 Demographic data of CAM userVS non-user

\begin{tabular}{|c|c|c|c|c|}
\hline Characteristic & & CAM user & Non-user & P value \\
\hline \multirow[t]{2}{*}{ Gender } & Male & 20 & 6 & 0.299 \\
\hline & Female & 66 & II & \\
\hline \multirow[t]{4}{*}{ Age (years) } & 7-Feb & 22 & 8 & 0.174 \\
\hline & I3-Aug & 38 & 6 & \\
\hline & $14-19$ & 24 & 3 & \\
\hline & $20-25$ & 2 & 0 & \\
\hline \multirow[t]{2}{*}{ Address } & Tripoli & 32 & 6 & 0.882 \\
\hline & Outside Tripoli & 54 & II & \\
\hline \multirow[t]{3}{*}{ Living with } & Mother & 2 & I & 0.152 \\
\hline & Father & I & I & \\
\hline & Together & 83 & 15 & \\
\hline Child education level & Preschool & 16 & 2 & 0.409 \\
\hline
\end{tabular}


Table continued...

\begin{tabular}{lllll}
\hline Characteristic & & CAM user & Non-user & P value \\
\hline \multirow{5}{*}{ Primary } & 36 & 12 & \\
Preparatory & 19 & 0 & \\
Secondary & 10 & 2 & \\
& University & 5 & 1 & 0.213 \\
Order of child in family & 4-Jan & 62 & 7 & \\
& 8-May & 19 & 10 & \\
& 12-Sep & 5 & 0 & \\
& First & 24 & 4 & \\
& 2nd & 18 & 3 & \\
& 3rd & 20 & 1 & \\
& 4th & 9 & 7 & 1 \\
& 5th & 4 & 1 & \\
& 6th & 3 & 0 & \\
\hline
\end{tabular}

$65(63 \%)$ of patients diagnosed as juvenile idiopathic arthritis, with mean disease duration of 5.27 years, five $(6 \%)$ of patients had comorbidity, two with epilepsy, other two with hepatitis, and one with bronchial asthma.

The prevalence of using CAM among Libyan children with rheumatic diseases in Tripoli hospital was $83 \%$ as shown in Figure 1.

Most of CAM user were females 66 (77\%), 38(44\%) of theme were aged 8 -13years, $54(63 \%)$ of CAM users were living outside Tripoli, $52(59 \%)$ Their education was preschool and primary school level, the median of family size was $4.57,87 \%$ represented first to third order in the family, $56(65 \%)$ of CAM users diagnosed as JIA, as shown in Figure 2.

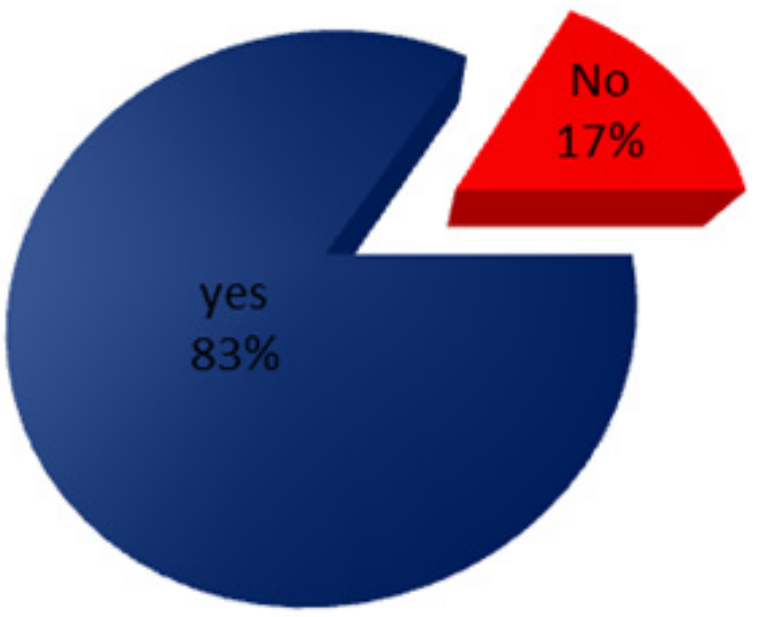

Figure I Percentage of CAM userVS nonuser.

Among those who used CAM in the past 20(23\%) were treated with methotrexate and biological drugs at the same time. A high percentage of CAM users (75\%) had disease duration between 1-7 years. None of the epidemiological factors as age of child, parent age, gender, education level, order of child, occupation of parent had any statistical significance. Disease duration had a significant impact on the prevalence of CAM use $(\mathrm{p}<0.009)$ Figure 3. More than half of CAM users $57(66 \%)$ used CAM because they thought it was natural and safe, $25(29 \%)$ were advised by others to use CAM, and $4(5 \%)$ had used CAM because their children had not improved with the use of conventional medicine. $46(53.5 \%)$ of CAM users used CAM after the diagnosis of disease while $30(34.9 \%)$ used CAM before diagnosis of their illness in rheumatology clinic. In 67(77.9\%) of CAM users, the issue was not discussed with their rheumatologist or other health care professional because $29(43.3 \%)$ of them had used CAM in the past, but saw improvement occurs on conventional medicine, 15(22.4 $\%$ ) were afraid from interaction of CAM with conventional medicine, $8(11.9 \%)$ thought that the physician was not satisfied with CAM use, $6(9 \%)$ had no information about CAM, $4(6 \%)$ were not advised to use it, $3(4.5 \%)$ was afraid from side effects of CAM, 2(3\%) was not satisfy with CAM.

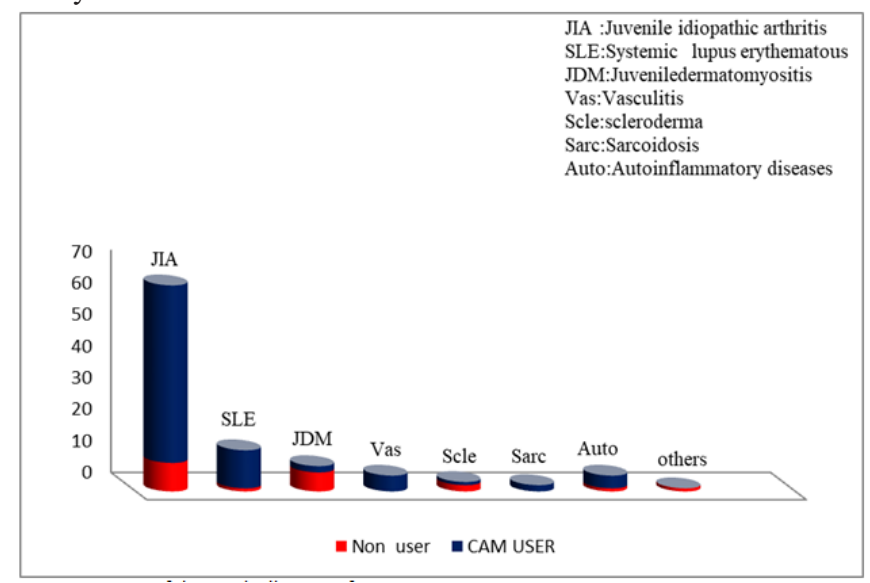

Figure 2 Types of rheumatic diseases of CAM userVS Non user.

On the other hand, 19(22.1\%) of CAM users had discussed the use of CAM with their health care provider, $15(17.4 \%)$ with a rheumatologist, $3(3.5 \%)$ with a physiotherapist, and $1(1.2 \%)$ with a CAM practitioner. About $81(94 \%)$ of CAM users had no trouble getting CAM, and only $5(6 \%)$ had difficulties getting CAM because the CAM practitioner was far from theme. The most frequently used CAM were Natural health products in $69.8 \%, 32 \%$ used herbal medicine orally such as Ginger, Bitter frankincense, Indian installment, 
Raisin, and Moringa, 7\% used an unknown mixture of herbs locally on the skin, while only $3 \%$ used mixture of herbs by inhalation. $51.7 \%$ used aromatherapy, $28 \%$ used honey, $62.8 \%$ used spiritual $/$ mind body therapies, all of them used Rukia, $38.4 \%$ used physical therapies, $22(66.7 \%)$ used cupping therapy, $8(24.2 \%)$ used cautery, $3(9 \%)$ used bees stings, $2(6 \%)$ used acupuncture, only one patient (3\%) used sand baths, and another one patient ( $3 \%$ ) used tormanium stone as shown in Figure 4-6 special nutrition used by one patient (1.2\%).

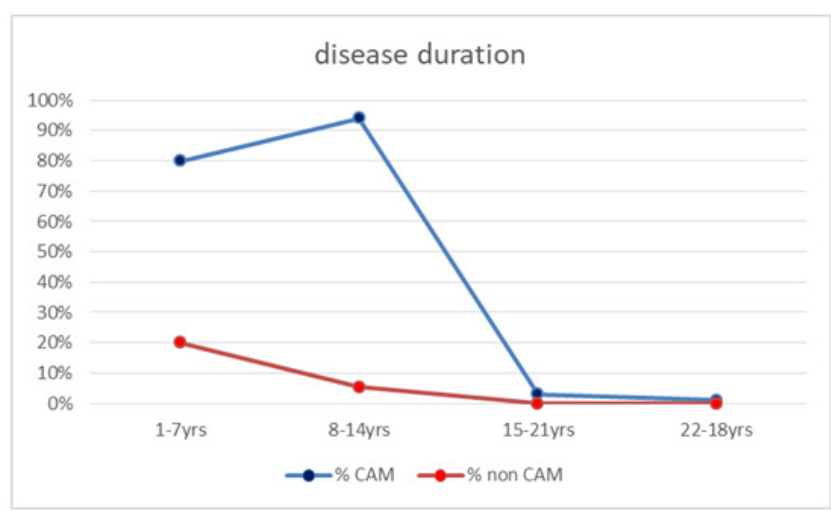

Figure 3 Disease duration in CAM vs Non CAM users.

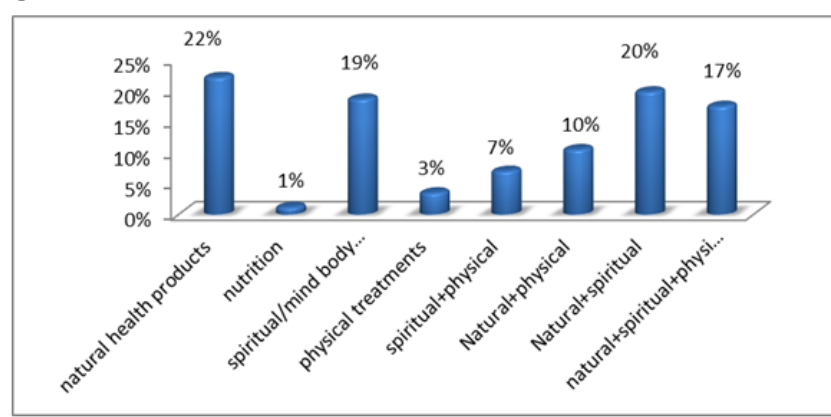

Figure 4 Types of CAM used.

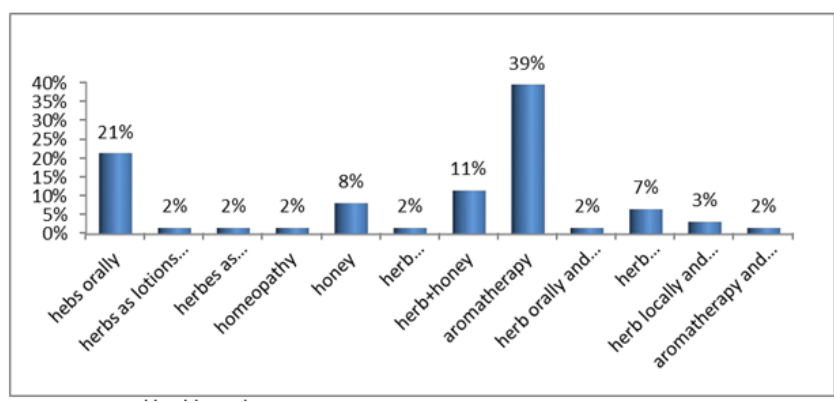

Figure 5 Natural health products.

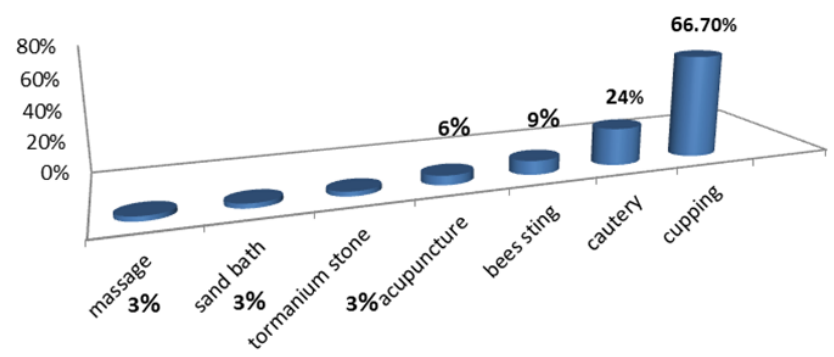

Figure 6 Physical treatments type.

$83(96.5 \%)$ of CAM users neither stopped their conventional medications nor deviated from their schedule's visits in rheumatology clinic. In 49 (57\%) of CAM users the parents discussed the possibility of using CAM with their children. The decision to start CAM was made by mothers in $40(46.5 \%)$ of CAM users, fathers in $14(16.3 \%)$, in $24(27.9 \%)$ both parents made the decision together. In $8(9.3 \%)$ decision made by other relatives.

The most frequently used CAM were natural health products, including herbal medicine, aromatherapy and honey followed by spiritual/mind body treatments (Rukia), then physical therapy such as cupping and bee's sting. 16(18.6\%) of previous CAM users start used CAM recently in the past two weeks ( $\mathrm{p}=0.054$ ), in $50 \%$ of these cases the parents shared the decision to use, and how to use CAM with their family, friends and their child rheumatologist.

Regarding reason to use CAM, $8(50 \%)$ patients used CAM because they thought it is natural and safe while $8(50 \%)$ patients used CAM because it was recommended by others

Regarding parents believe in benefit of CAM, 14 (87.5\%) of CAM users in the past two weeks felt that the CAM was helpful and $2(12.5 \%)$ felt that the CAM was not helpful, $10(62.5 \%)$ felt better, $2(12.5 \%)$ had less pain, $2(12.5 \%)$ had more energy, with no benefit $2(12.5 \%)$. Their believes on safety ranged from absence of any side effects in $11(68.8 \%)$, to no benefit at all in $1(6.5 \%)$.

$17(16.5 \%)$ of total participants never used any type of CAM, in $6(35.3 \%)$ of these cases their parents believed it would not improve their child's health, $4(23.5 \%)$ had no knowledge on CAM, 2(11.8\%) afraid of side effects, $2(11.8 \%)$ were afraid of interaction with conventional medicine, $2(11.8 \%)$ did not use CAM because it was not recommended by health care team, and only one (5.9\%) did not find it.

We found that $43(42 \%)$ of total patients were planning to use CAM in future, $17(39.5 \%)$ wanted to use natural health products, $88 \%$ preferred herbal therapy, 17 patients wanted to use physical therapy, $82 \%$ wanted to use cupping, and $9(21 \%)$ wanted to use spiritual mind body treatments such as Rukia. (54\%) of the participants did not plan to use CAM in the future, while $42 \%$ planning to use CAM in future.

\section{Discussion}

To our knowledge, our present study is the first pediatric survey conducted in Libya and Arab countries on the use of CAM in children with rheumatic diseases, in this cross-sectional questionnaire study, we found that the prevalence of CAM use was $83 \%$. This is significantly higher when compared with $33.9 \%$ of children with JIA in Montreal Children's Hospital-McGill University Health Centre and British Columbia's Children's Hospital and $14.7 \%$ of Italian pediatric patients in rheumatology clinic. ${ }^{12,13}$ And this may reflect the cultural diversity and the attitude of the Arabic Muslim population compared with European population. Also, this percentage is higher than in children with inflammatory bowel disease and juvenile arthritis in Finland, where the prevalence was $81 \%{ }^{20}$

$77 \%$ of CAM users were female partially because rheumatic disease in general affects females more than males. The age of CAM users ranged from 8 to 19 years, which means that use of CAM increased as patients get older. The education level was primary and preschool level in $60 \%$ of patients and this reflects the early use of CAM in young children with rheumatic diseases trying to prevent complications of such diseases.

$62.7 \%$ of CAM users coming from outside Tripoli, despite the fact that these treatments still have unknown mechanism of action and need further investigation and scientific evidence to support their safety, people in the rural areas are more likely to think about the use 
of CAM than the people living in cities and this may be explained partially by poor health services in these areas.

Most CAM users (96.5\%) were living with their father and mother together and this is the normal situation in our community. This high percentage may reflect the higher level of care in well-structured families. Regarding parents' level of education, $80 \%$ of CAM user parents were highly educated. This is much higher than what Sgarlat 2011 found, who reported that in $50 \%$ of pediatric patients who used CAM their parents were at college level or higher.

All illiterate parents 10/86 (11\%) used CAM and this may reflect the culture of the Libyan community as CAM is well known from long time ago and most of the Libyans are friendly with CAM and use it frequently in their life also, the prophet medicine is commonly applied. Although socioeconomic factors enhanced CAM utilization, ethnicity and geographic nature makes Libya good area for CAM diversity such as herbal medicine, cupping and body-mind therapy (Rukia).

Chronic disease has been reported to be associated with CAM use in children, but research on pediatric patients is limited. JIA patients form $65 \%$ of total patients and $86 \%$ of them used CAM. In North America, CAM use among both pediatric IBD and JIA patients is considerably more common than among healthy children. ${ }^{20}$

$80 \%$ of patients with disease duration 1-7 years used CAM, and this percentage increased to $94 \%$ in those with disease duration of $8-14$ years $(p<0.009)$, this is similar to what Hagen and Nousiainen found. ${ }^{11,20}$ But of note in our patient, use of CAM reduced to non-use in all patient above 15 years disease duration. This may be explained that longer disease duration was strongly associated with CAM use early in the disease and this is quite expected as chronic disease and its complications such as joint deformities and its effect on normal physical activities make the family looking for other modalities of treatment like use of CAM but as the disease lasts longer the interest of using other modalities of treatment disappeared.

$4.8 \%$ of our patients had co-morbidity and all of them used CAM, our results were similar to Hagen study who found that children with co-morbidity were more likely to use CAM, these patients who have more than one disease are worried that using a multiple chemical drug may cause side effects after chronic use and may interfere with each other leading to decrease effectiveness or toxicity, therefore they tend to seek another natural and safe treatments. Also, co morbidity can affect multiple organs which may affect the psychological state of the patient causing him to change or even stop his medication. A large number of CAM user $(96.5 \%)$ were on regular treatment and $23.3 \%$ of them were on methotrexate and biological drugs together, and this high percentage of CAM use in such patients reflects the severity and aggressiveness of disease making theme searching for other treatment modalities.

In most parents, $77.9 \%$ the issue of CAM use was not discussed with their rheumatologist or other health care provider, they were unable to talk to ask the physicians particularly when their children had improved with the use of conventional medicine simply because they thought that the physician will not agree to use CAM for their patients, or not satisfy with CAM. Most of the physician did not discuss the use of CAM possibly due to poor information which makes the physicians unable and refuse to discuss this issue with parents. In the other hand, $22.1 \%$ discuss using CAM with health care provider; $17 \%$ with a rheumatologist, $3.5 \%$ with a physiotherapist and $1.2 \%$ with a CAM provider.
In Sgarlat's study $66 \%$ of parents did not disclose the use of CAM to the pediatric rheumatologist although $43 \%$ of CAM users reported disclosing CAM use with other health care providers including pediatricians, pediatric nurse, social worker, phycologist and complementary medicine provider. Of those parents who did discussed use of CAM with the provider, $60 \%$ reported that they felt that their provider approved CAM, $28 \%$ had no opinion and $12 \%$ was disapproved CAM use. ${ }^{9}$

Zebrack $\mathrm{i}^{10}$ reported that $45 \%$ of CAM users indicated that their rheumatologist was not aware of their use of CAM and the issue was not discussed because of their negative repose toward CAM. CAM was used after confirming the diagnosis in a rheumatology clinic in $53.5 \%$ of patients and this may be due to a better understanding of the chronic nature of the disease and risk of complication.

Regarding types of CAM, natural health products were the most frequently used in the form of aromatherapy, herbal medicine, and honey, respectively followed by Rukia then cupping both of theme considered as the prophet and traditional medicine applied in Islamic countries, while homeopathy, yoga and, chiropractic therapy, are rarely used in Libya. Our results were similar to Sgarlat results which found that $69 \%$ of the patients used natural products, but $55 \%$ used mind body medicine such as yoga which is not found in our patients, $40 \%$ used manipulative medicine such as chiropractic therapy.

Hagen et al noticed that vitamins and minerals were the most commonly used CAM in pediatric patients attending an outpatient rheumatology clinic in a major tertiary care referral center. In our study vitamins and minerals are not considered as a CAM. 49(57\%) of parents talked with their children about the use of CAM while $37(43 \%)$ did not and this may relate to the child's age as older children are likely to understand the issue.

Surprisingly, $96 \%$ of users were on a regular follow-up and did not stop or change conventional treatment, conversely, in Italian children with rheumatic diseases, those who used CAM, $24 \%$ of theme deviated from follow up for more than one year and even stopped conventional treatments after starting CAM compared with only $10 \%$ who were in regular follow-up while using CAM, those who deviated from followup were unsatisfied with conventional medicine, and they believed that there was no benefit, also they afraid of possible side effects and interaction between conventional drugs and CAM. ${ }^{11}$

$66 \%$ of CAM users believed that CAM is natural and safe, and there is no any significant adverse effect. Despite that all types of CAM have no clear mechanism of action and need further investigations to study their safety. The decision to use CAM was made by mothers in $46.5 \%$ of CAM users, while both parents shared the decision in $28 \%$ of users, and this may reflect the position of the mother in the direct care of children in Libyan families.

$19 \%$ of our patients who used CAM recently in last two weeks were satisfied with CAM and they felt better, and the parents felt that their children became more active. Also, they believed that herbal medicine and prophet medicine as Rukia, and cupping were helpful at the same time they are natural and safe therapy. $68.8 \%$ of recent CAM users had no any adverse effects, and the only problem with CAM was the long duration that was needed to show any effect as $18.8 \%$ of parents believed.

Zebracki found that CAM was used to manage pain in JIA patients with improvement in overall well-being in $90 \%$, while Sgarlat reported that CAM users were happy with the results of treatments, with significant improvement in $49 \%$. 
In our study, CAM was not significantly associated with any demographic characters as age, gender, type of rheumatic disease, address, and education level of parents, questionable relation with mothers age $(\mathrm{P}=0.04)$. They only significant factor we could found is the disease duration $(\mathrm{P}=0.009)$, this is similar to what Hagen found, disease duration was strongly associated with CAM use. It should be noted that disease duration does not really means active disease within this time frame.

CAM use was highly associated with parental use of CAM and family income, as families with low income are less likely to use CAM11, but both these factors does no looked for in our study. But Questioning the parents about possible use of CAM in future shows that $42 \%$ of parents were planning to use CAM for their children in the future,16(37\%) from them were CAM users, this group may satisfy with CAM use and get benefit without complaining from any side effects. The other $54 \%$ were not interested with use of CAM specifically when their children were improved on conventional medicine or some of them were afraid from side effects or interaction of CAM with these medications.

\section{Conclusion \& recommendation}

We concluded that CAM use is prevalent in pediatric rheumatology patients, most of them were female with highly educated parents living in small family, natural health products were the most commonly used CAM. Although most rheumatology patients used CAM few deviated from follow-up and continued on conventional therapy in addition to CAM. Larger surveys are required to verify the results of this study and to better elucidate reasons influencing CAM use, as well as validate safety and benefit of different types of CAM used by Libyan patients. Physicians should familiarize themselves with the basic concepts of CAM and actively ask their patients about their CAM use. Education and counseling programs to patients and parents about CAM use are needed. Introduce some types of CAM such as natural products, massage, and reflexology in treatment of rheumatic diseases. Increased emphasis on teaching complementary medicine in the faculties of pharmacy and medicine.

\section{Acknowledgments}

None.

\section{Conflicts of interest}

The authors declare there are no conflicts of interest.

\section{Funding}

None.

\section{References}

1. Roberti P. The social demand for a medicine focused on the person: the contribution of cam to healthcare and healthgenesis. Evid Based Complement Alternat Med. 2007;4(Suppl 1):45-51.

2. Dhankar M. Complementary and alternative medicine: a cross-sectional observational study in pediatric inpatients. J Evid Based Integr Med. 2018;23:2515690X18765119.

3. WHO. Guidelines on developing consumer information on proper use of traditional, complementary and alternative medicine. 2004.
4. Ball SD, Kertesz D, Moyer-Mileur LJ. Dietary supplement use is prevalent among children with a chronic illness. $J$ Am Diet Assoc. 2005;105(1):78-84.

5. Armishaw J, Grant CC. Use of complementary treatment by those hospitalized with an acute illness. Arch Dis Child. 1999;81(2):133-137.

6. Day AS, Whitten KE, Bohane TD. Use of complementary and alternative medicines by children and adolescents with inflammatory bowel disease. J Pediatr Child Health. 2004;40(12):681-684.

7. Southwood TR, Malleson PN, Roberts-Thomson PJ, et al Unconventional remedies used for patients with juvenile arthritis. Pediatrics. 1990;85(2):150-154.

8. Caitlin M Sgarlat. Complementary and Alternative Medicine in Pediatric Rheumatology. Master degree in clinical Research and Translational Science. Sackler School of Graduate Biomedical Sciences. USA: Tufts university; 2011

9. Zebracki K, Holzman K, Bitter KJ, et al. Brief report: use of complementary and alternative medicine and psychological functioning in Latino children with juvenile idiopathic arthritis or arthralgia. $J$ Pediatr Psychol. 2007;32(8):1006-1010.

10. Lorrie EM Hagen, Rayfel Schneider, Derek Stephens, et al. Use of Complementary and Alternative Medicine by Pediatric Rheumatology Patients. Arthritis Rheum. 2003;49(1):3-6.

11. Feldman DE. Ciaran D, Mirella DC, et al. Factors associated with the use of complementary and alternative medicine in juvenile idiopathic arthritis. Arthritis Rheum. 2004;51(4):527-532.

12. Fadanelli G, Vittadello F, Martini G, et al. Complementary and alternative medicine (CAM) in paediatric rheumatology: A European perspective. Clin Exp Rheumatol. 2012;30(1):132-136.

13. Kathi J Kemper, Sunita Vohra, Richard Walls. The Use of Complementary and alternative medicine in pediatrics. Pediatrics. 2008;122(6):1374 1386.

14. Munevver Tulunay, Cenk Aypak, Hulya Yikilkan, et al. Herbal medicine use among patients with chronic diseases. J Intercult Ethnopharmacol. 2015;4(3):217-220.

15. Kamaruzaman H. Health technology assessment section medical development division. Ministry of health Malayzia. 2012.

16. Haswani N, Yee Chang, Long Chiau, et al. Revisiting reflexology: Concept, evidence, current practice, and practitioner training. $J$ Tradit Complement Med. 2015;5(4):197-206.

17. Inas Rifaat Ibrahim, Mohamed Azmi Hassali, Fahad Saleem, et al. The History of Traditional Medicine in the Arab Region. Journal of Complementary Medicine \& Alternative Healthcare. 2017;4(2):2-4.

18. Alrowais NA, Alyousefi NA. The prevalence extent of Complementary and Alternative Medicine (CAM) use among Saudis. Saudi Pharm J. 2017;25(3):306-318.

19. Karine Toupin April, Jennifer Stinson, Heather Boon, et al. Development and Preliminary Face and Content Validation of the "Which Health Approaches and Treatments Are You Using ?" (WHAT) Questionnaires Assessing Complementary and Alternative Medicine Use in Pediatric Rheumatology. PLoS One. 2016;11(3):e0149809.

20. Pauliina Nousiainen, Laura Merras-Salmio, Kristiina Aalto, et al. Complementary and alternative medicine use in adolescents with inflammatory bowel disease and juvenile idiopathic arthritis. $B M C$ Complement Altern Med. 2014;14:124 